\title{
Where are the Alien Species? Predictions of Global Plant Species Invasions under Current Environmental Conditions and the Human Footprint
}

\author{
Yao Wang ${ }^{1}$, Zhonglin $\mathrm{Xu}^{2 *}$ \\ ${ }^{1}$ The Meteorological Bureau of Changji, Changji 831100, China \\ ${ }^{2}$ College of Resource and Environmental Science, Key Laboratory of Oasis Ecology of the Ministry of Education, \\ Xinjiang University, Urumqi 830046, China
}

Received: 11 August 2015

Accepted: 7 March 2016

\begin{abstract}
Species invasion is a significant concern because of its substantial effect on native ecosystems. A number of species-specific invasion predictions that correspond to environmental conditions are available, but literature predicting global species invasion that corresponds to environmental conditions and human activity is scarce. In this study, the potential geographic ranges of 308 alien plant species were predicted under current environmental conditions and human activities. Environmental conditions were delineated by bioclimatic (mean annual temperature, mean annual precipitation, mean temperature of wettest quarter, and precipitation of driest quarter) and topographic variables (annual solar radiation and topographic wetness index). Human activity was delineated by the human footprint, which is a raster data layer created from nine global data layers that describe human population pressure, land use and infrastructure, and human access. The potential distribution of the target species was predicted using the different types of models. By searching the correlated literature, we identified and excluded the native geographic range of the studied species in the predicted geographic range to obtain the exclusive invasive range. Results demonstrated that the invasion hotspots included the southern part of North America, Southern and Western Europe, the south coast of Asia, coastal regions of Australia and New Zealand, the coast of West Africa, the Ivory Coast of Africa, and the southern part of Brazil. In addition, the land areas of the low- (proper for less than 50 alien species), moderate- (51-100 aliens), and high-risk regions (more than 100 aliens) are 213.23, 18.15, and 2.50 million $\mathrm{km}^{2}$, respectively. All variables (bioclimatic and topographic variables and human footprint) were positively correlated with increasing richness of alien species. The highest correlation coefficient was obtained for the human footprint.
\end{abstract}

Keywords: species distribution modeling, global, invasion potential, assembled modeling

*e-mail: galinwa@qq.com 


\section{Introduction}

Invasions by alien species can cause a rapid decline of native species [1]. An invasive alien species that dominates a native ecosystem and outcompetes native species can alter the functions of the ecosystem [2]. Therefore, the invasive potential of alien species should be predicted. The distribution of invasive species is important in invasion studies and is at the core of conservation planning [3-7]. Distribution is a consequence of environmental condition, and potential distribution is used to discover quantitatively the response of invasive species to variations in environmental conditions. The actual distribution of alien species is difficult to obtain because of the expensive and time-consuming process involved. Remote sensing technology is beneficial for timely investigation of large spatial-scale land surfaces; however, the spatial resolution of remotely sensed data cannot obtain the actual distribution and monitor the dispersal of alien species [4]. The potential distribution of alien species can be predicted using invasive species distribution models [5].

The correlation between alien species occurrence and environmental condition is constructed in their native (and/or invaded) region and then applied in regions without an occurrence record to predict the potential distribution of target species. This process is called spatial extrapolation of species distribution model and is mainly used to delineate spatial dispersal prediction of species [6]. Temporal extrapolation is another method used in species distribution models. In this method, the constructed relationship is applied to different time points (past or future) to obtain the potential distribution of alien species [6]. This technique is feasible when obtaining information regarding the past dispersal history or future dispersal potential of alien species. Some studies have focused on the use of species-specific prediction to determine potential invasion [7-9], but literature on global species invasion under current environmental conditions is limited.

Understanding the dispersal or invasion procedure of alien species is a major challenge, particularly the mechanism by which climate delineates the geographic distribution of invasive species $[10,11]$. The spatial extrapolation of species distribution models can reveal the underlying mechanism that controls the range shift of alien species. The environmental (or non-environmental) conditions that affect the distribution of invasive species should be collected to bring about spatial extrapolation. Environmental conditions can be depicted using climatic, topographic, and other variables. However, the distribution of invasive species cannot be delineated with these "natural" variables alone because human activities strongly affect the dispersal of alien species directly and indirectly. Direct influence includes the introduction of alien species outside their native geographic ranges to obtain food, medicine, recreation, and other commercial benefits [12]. Indirect influence, such as anthropogenic elimination of native species, can promote alien species invasion; eliminating native species is advantageous for alien species when competition exists [13]. The influence of human activities on alien species has been studied for different species at different spatial scales $[9,13-16]$. However, the mechanism by which global species invasions respond to human activities is not clearly elucidated, particularly when human activities and climatic variation are considered. Thus, the global geographic trend of alien species should be modeled in consideration of human activities and climatic variation.

This study predicted the global potential distribution of 308 alien species (Supplementary Table S1) and examined the correlation between global geographical patterns of alien species distribution and human activities. The proposed prediction and relationship analyses are important in native ecosystem protection and plant conservation. The proposed technique may also elucidate the underlying mechanisms that control the response of alien species to environmental conditions and human activities.

\section{Experimental Procedure}

Data

Species occurrence data were collected from the Global Invasive Species Database (GISD) [17] managed by the Invasive Species Specialist Group under the International Union for Conservation of Nature and Data Portal of the Global Biodiversity Information Facility [18]. The GISD focuses on invasive alien species that negatively affect native biodiversity and natural ecosystems. The database also covers all taxonomic groups from microorganisms to animal and plant species in all ecosystems. The occurrence data in the database were collected and provided by more than 1,000 invasion biology scientists with expertise on all taxonomic groups and environments [1]. The Global Biodiversity Information Facility is an international open data infrastructure that operates through a network of nodes. This database allows free access to species data and facilitates biological and environmental research correlated with biodiversity. A total of 308 selected species (107 herbs, 81 trees, 24 vines, 12 aquatics, 24 grasses, two alga, two sedges, one rush, three palms, and four ferns) are listed in Supplementary Table S1. Several of these species are listed by the International Union for Conservation of Nature as 100 of the world's worst invasive alien species [19], and the other 108 species have the most occurrence records worldwide, according to the GISD.

These species were selected because of their significant effects on biodiversity and intensive threats to different ecosystems. We identified the native and invasive ranges of each species after an intensive literature search, as demonstrated in Table S1. The native range of several species (i.e., Central Asia) cannot be depicted by borders among different countries; thus, relatively broader geographic ranges should be defined. For example, Central Asia mainly includes Kazakhstan, Kyrgyzstan, Tajikistan, 
Turkmenistan, and Uzbekistan. Twenty-five ranges were defined in this study, namely East Africa, Middle Africa, North Africa, South Africa, Western Africa, Latin America and the Caribbean, Central America, South America, North America, Central Asia, Eastern Asia, Southern Asia, Southeast Asia, Western Asia, Eastern Europe, Northern Europe, Southern Europe, Western Europe, Oceania, Tropical Asia, Tropical America, the Indian subcontinent, the Middle East, the Mediterranean, and Central Europe. The administrative regions of these ranges are presented in Table S1.

Climatic variables are the most important factors that determine the relationships between species occurrence and environmental conditions [1, 7, 10]. This study used climatic variables from the Worldclim dataset [20], which utilizes 19 bioclimatic variables (interpolated using a $0.5^{\circ}$ spatial resolution) to characterize the existing temperature- and precipitation-related climatic conditions. These variables are important in maintaining species populations. However, high collinearity exists among the 19 variables; consequently, overfitting may occur when modeling the potential distribution of the target species. Therefore, only a subset of the dataset was selected for modeling. We specifically used mean annual temperature (MAT), mean annual precipitation (MAP), mean temperature of wettest quarter (TWQ), and precipitation of driest quarter (PDQ) to characterize climatic conditions. We also used topographic wetness index (TWI) and annual solar radiation (ASR). These two variables were calculated based on the global digital elevation model (DEM) according to the method of Beven and Kirkby [21]. TWI and ASR were selected because several studies have revealed their strong correlation with the spatial distribution of plant species [22-25]. Moreover, the influence of human activities was included in modeling the spatial distribution of plant species. Therefore, we used the human footprint (HFP) as an index to delineate the characteristics of human activities. HFP ranges from " 0 " (no human activity) to " 100 " (most intensive human activity). Its value is derived from nine global data layers that include human population pressure, land use and infrastructure, and human access (coastlines and roads) [26]. TWI and ASR were originally calculated based on DEM with a 30 arc-second resolution, which is similar to the resolution for collecting HFP, to maintain a similar spatial resolution to that of bioclimatic variables (resolution is $0.5^{\circ}$ ). We resampled the resolution of these three variables with the MAJORITY algorithm.

\section{Species Distribution Modeling}

The potential distribution of target plant species can be modeled by combining the collected occurrence records and variables that are assumed to be crucial for species invasion. This combined approach is used to determine the relationship between species occurrence and the considered variables. The application of the relationship at a relatively broader spatial scale (or in another temporal period) can predict potential species distributions. The use of species distribution models, which consist of different models based on different algorithms, is a feasible method to obtain the potential distribution of target species. In this study, nine different species distribution models were used within the ModEco platform [27]. These models are BioClim [28, 29] (Busby 1986, Carpenter et al., 1993), DOMAIN [26], generalized linear model, artificial neural network, support vector machine, classification tree, maximum likelihood, rough set, and maximum entropy. The BioClim model identifies locations where all environmental variables fall within certain percentiles (e.g., 95\%) of the observation records. Thus, BioClim defines the environmental envelope for target species as a hyperbox (Carpenter et al., 1993). The DOMAIN model assigns a classification value to an unknown site based on the distance of its closest similar site in environmental space. This model is analogous to the nearest neighbor classification and is considered an improvement over the BioClim model [29]. Generalized linear model is a generalization of the general linear model and is commonly used to model dependent variables that are discrete distributions and are nonlinearly related to independent variables (via a link function that transforms the scale of the dependent variable) [30]. Artificial neural networks extract linear combinations of the input variables and model the output as a nonlinear function of these variables [31]. In the ModEco platform, a four layer feedforward artificial neural network (one input, one output, and two hidden layers) trained with the backpropagation algorithm is implemented [32].

Support vector machines are designed for two-class problems where both positive and negative objects exist (in this study, both the presence and absence of targets species); in this situation, the model seeks to find a hyperplane in the feature space (environmental variable space) that maximally separates the two target classes. Support vector machines have several advantageous characteristics for modelers [33]. Classification trees seek to partition the response variable recursively into increasingly pure binary subsets with splits and stop criteria [34]. The maximum likelihood method labels an unknown location to the class (either presence or absence) of the maximum likelihood. The likelihood is defined as the posterior probability of the unknown location belonging to either presence or absence [34]. The rough set method is a mathematical tool that deals with a vague concept based on reduction; this model is particularly useful for rule generation and feature selection in data mining [35]. The maximum entropy model was developed based on the principle of maximum entropy, under which a target probability distribution can be determined by finding the probability distribution of maximum entropy, which is subject to a set of constraints that represent incomplete information regarding the target distribution [36].

BioClim, DOMAIN, and the support vector machine use presence-only data when modeling potential distribution of target species, whereas a presence-absence record is necessary for other models (maximum likelihood and generalized linear model). The "pseudo-absence" 
records were generated from the entire study area because of the lack of absence data. The number of pseudoabsences for each species was generated according to a previously published method [1]. The potential distribution results predicted by these models included binary ("1" for proper and " 0 " for improper) and probability (" 0 " for most improper to " 1 " for most proper) formats. Moreover, the predictions in the probability formats should be converted into binary format. The present study used an approach for maximizing the sensitivity and specificity for the conversion [37]. After the modeling and conversion procedures, nine prediction layers (with binary value) were obtained for each of the 308 species.

\section{Model Performance Evaluation}

The collected presence records (and/or absence records) were divided into calibration and evaluation sets to model the potential distribution of the target species. We used $75 \%$ of the records for calibration and $25 \%$ for evaluation for each species. Model performance was evaluated by calculating true skill statistics (TSS) [38]. The value of TSS can be calculated from a prediction error matrix, which consists of true positive $a$ (recorded present and predicted present), false positive $b$ (recorded absent and predicted present), false negative $c$ (recorded present and predicted absent), and true negative $d$ (recorded absent and predicted absent). The value of TSS can be obtained by calculating the value of $S e+S p-1$, where $S e$ is the sensitivity and equal to $a /(a+b)$ and $S p$ is the specificity and equal to $d /(c+d)$. TSS ranges from -1 to +1 , where +1 indicates perfect agreement; values of zero or lower indicate inferior performance to the random values [38]. TSS considers the commission and omission errors; its value is unaffected by the size of the validation set; thus, TSS has been widely used to evaluate model performance [37].

We obtained nine prediction maps for each species by applying the nine models. As previously mentioned, these maps are binary, with " 1 " for predicted presence and " 0 " for absence, to indicate the potential distribution of the target species. Thus far we have obtained nine binary prediction maps for each species and selected the map with the highest TSS value as the final prediction for each species. In addition, we obtained 308 prediction maps correlated with the potential distribution of all alien species. These maps also included the native range of the species, which were removed using the methods reported in published papers (Supplementary Table S1). Subsequently, the predicted invasion-only areas of all species were obtained. We added the 308 invasion-only maps of all species to achieve the final invasion potential of all alien plant species.

\section{Results}

The TSS values for 308 modeled species ranged from 0.66 (when modeling the potential distribution of Cuphea ignea) to 0.85 (corresponding to Rubus discolor). More than $95 \%$ (199) of the models exhibited TSS value higher than 0.70 , thereby indicating reliability of the correlated predictions.

The hotspots for alien plants include the southeast United States, Eastern South America, Southwest Europe, Central and Southeast Africa, Southeast Asia, Southeast Australia, and New Zealand. The blue-shaded regions in Fig. 1 (i.e., the northern part of North America, the majority of Asia, North Africa, the Indian subcontinent, and inland regions of Australia) are relatively improper for species distribution and/or invasion. The red-shaded regions, including the previously mentioned hotspots as well as the east and west coasts of Africa and East Asia, are relatively more proper.

Fig. 2 shows the regions with different risk levels of species invasion. As demonstrated in Fig. 2a, the greyshaded regions are influenced by less than 50 alien species and are classified as low-risk. The yellow-shaded

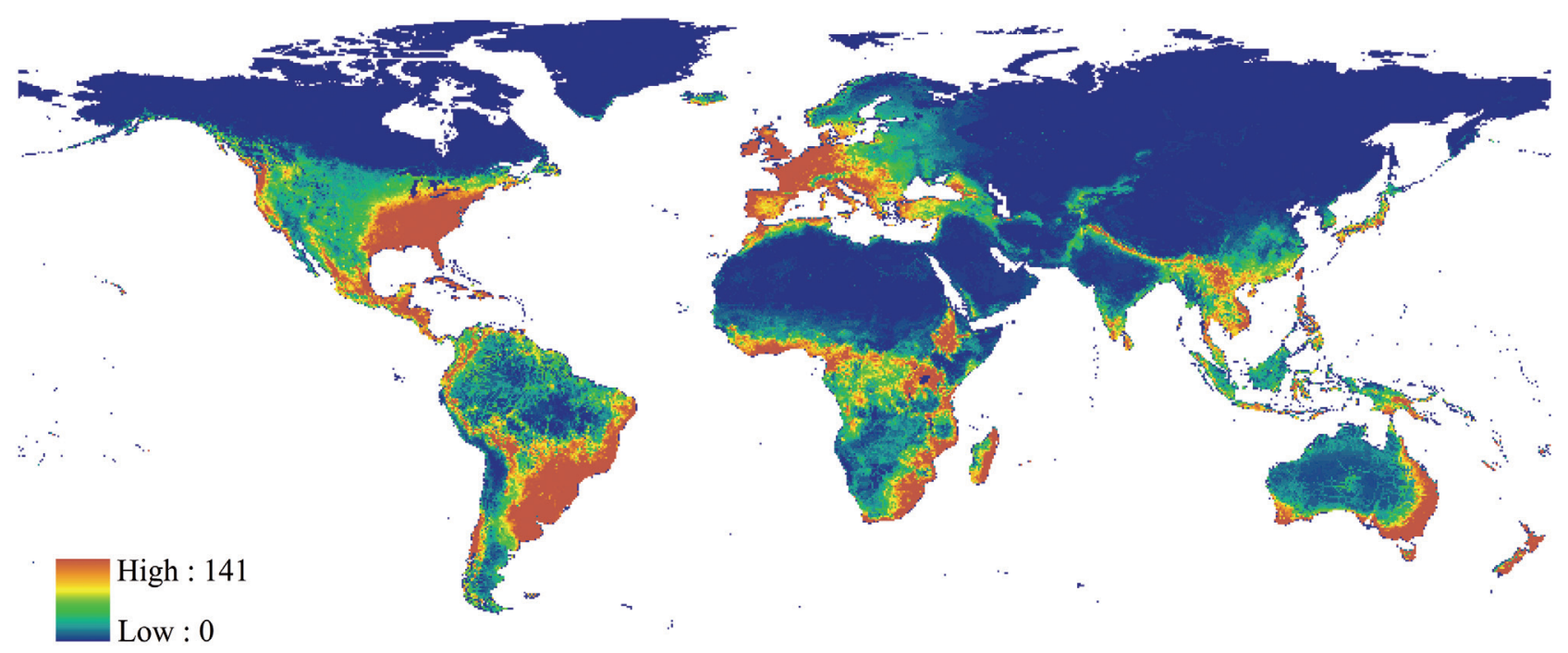

Fig. 1. Modeled hotspots for alien plants. 


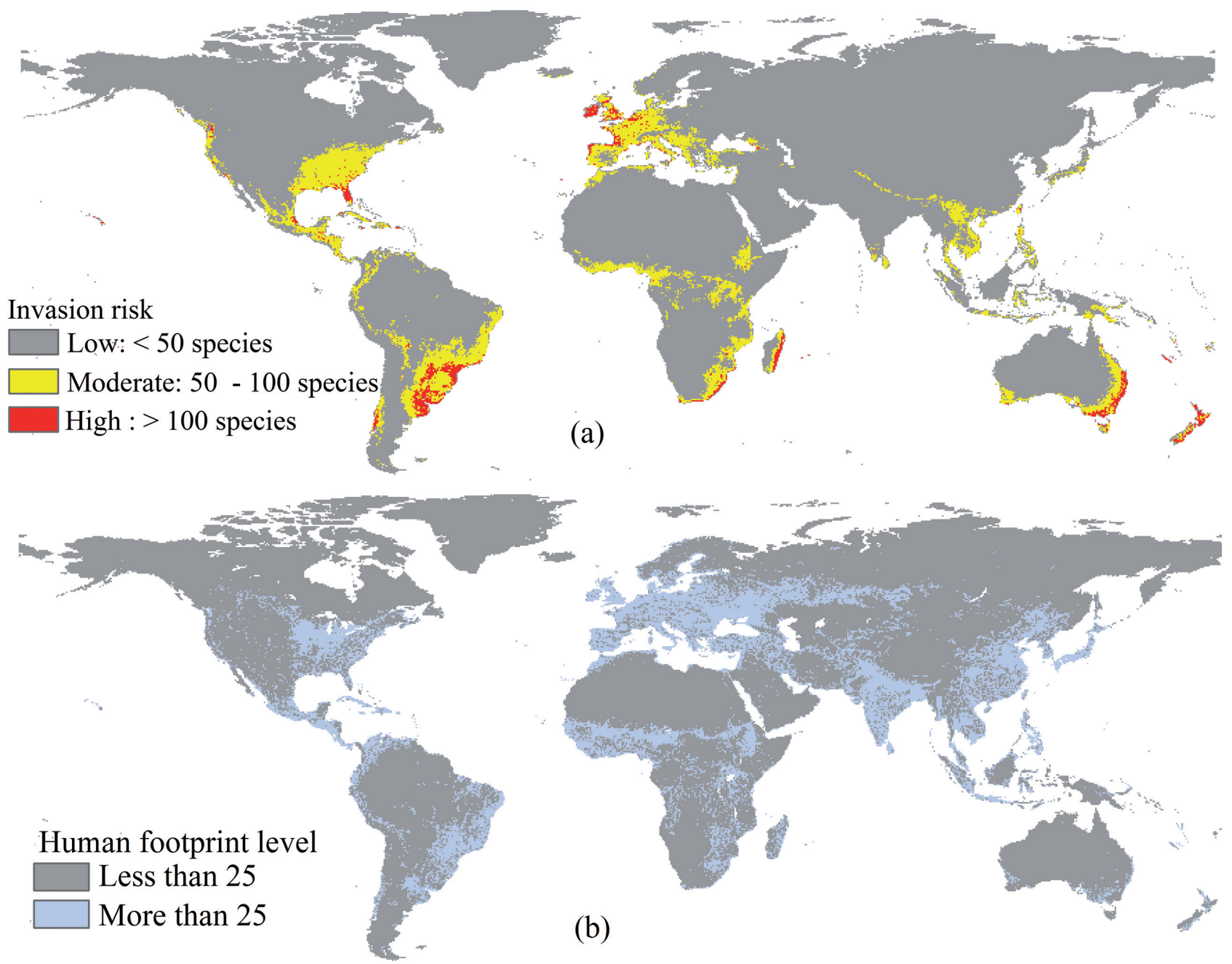

Fig. 2. Regions with different risk levels of species richness and human activities (HFP). Regions with high species richness are closely related to those with high levels of human activities.

regions are classified as moderate-risk and projected to be influenced by 51 to 100 alien species. The red-shaded region can be influenced by more than 100 species and are considered as high-risk regions. The land areas of the low-, moderate-, and high-risk regions are 213.23, 18.15, and 2.50 million $\mathrm{km}^{2}$, respectively.

Table 1 demonstrates the correlation coefficient between the considered variables (four bioclimatic variables, TWI, ASR, and HFP) and alien species richness. Among the four bioclimatic variables, the temperaturerelated variables (MAT and TWQ) exhibited higher correlation coefficients with the alien species richness than the precipitation-related variables (MAP and PDQ). The topographic variables (TWI and ASR; 0.42 and 0.39 correlation coefficients, respectively) were more closely related to alien species richness than the bioclimatic variables. The highest correlation coefficient was obtained for HFP (0.51). All correlation coefficients demonstrated in Table 1 were positive. Thus, these variables were positively correlated with the richness of alien species. That is, higher variable value indicated more abundant alien species.

A close relationship between alien species richness and HFP is also demonstrated in Fig. 2 (Pearson's $\mathrm{r}=0.56, \mathrm{p}<0.01)$. The yellow- and red-dashed regions in Fig. 2 a (regions with more than 50 species invasions) closely matched the yellow-dashed regions in Fig. 2b (regions with HFP higher than 25).

Table 1. Correlation coefficients between the variables and alien species abundance $(p<0.01)$.

\begin{tabular}{|c|c|c|c|c|c|c|c|}
\hline Predictors & MAT & MAP & TWQ & PDQ & TWI & ASR & HFP \\
\hline Correlation coefficient with alien species abundance & 0.36 & 0.21 & 0.37 & 0.29 & 0.42 & 0.39 & 0.51 \\
\hline
\end{tabular}

MAT: mean annual temperature, MAP: mean annual precipitation; TWQ: temperature of the warmest quarter, PDQ: precipitation of the driest quarter, TWI: topographic wetness index, ASR: annual solar radiation, HFP: human footprint. 
Table 2. Top 10 invasive species with the largest potential distribution area and those with the least potential area.

\begin{tabular}{|c|c|c|c|}
\hline 10 invasive species with largest potential distribution area & \multicolumn{2}{|c|}{10 invasive species with least potential distribution area } \\
\hline Species name & $\begin{array}{c}\text { Potential distribution area } \\
\left(\mathrm{M} \mathrm{km}^{2}\right)\end{array}$ & Species name & $\begin{array}{c}\text { Potential distribution area }(\mathrm{M} \\
\left.\mathrm{km}^{2}\right)\end{array}$ \\
\hline Rattus rattus & 37.47 & Eleutherodactylus coqui & 0.035 \\
\hline Ricinus communis & 36.12 & Polistes chinensis antennalis & 0.035 \\
\hline Alternanthera sessilis & 34.42 & Mustela furo & 0.038 \\
\hline Cyperus rotundus & 32.74 & Mustela nivalis & 0.04 \\
\hline Acacia farnesiana & 31.94 & Dioscorea oppositifolia & 0.14 \\
\hline Chromolaena odorata & 28.82 & Myrmica rubra & 0.23 \\
\hline Cynodon dactylon & 28.56 & Chenopodium hybridum & 0.58 \\
\hline Phragmites australis & 28.37 & Calliphora vicina & 0.69 \\
\hline Hibiscus trionum & 28.35 & Cymantria dispar & 0.94 \\
\hline Lantana camara & 28.07 & Carijoa riisei & \\
\hline
\end{tabular}

\section{Discussion}

Invasive alien species extend in different geographic regions depending on their invasiveness and environmental condition. Therefore, the potential area of distribution for each species may differ. In order to compare the invasiveness of plant species and other invasive species, we also predicted the potential distributions other species that has been listed in 100 World's Worst Invasive Alien Species [19] but were not included in this study (as presents in Table S1). We further calculated the potential invasive area for all the target species and found that this area ranges from 0.035 million $\mathrm{km}^{2}$ to 37.47 million $\mathrm{km}^{2}$, with an average of 4.73 million $\mathrm{km}^{2}$. To our knowledge, this report is the first of similar studies that estimate the potential distribution area of invasive species on a global scale. We present 10 species with the maximum potential distribution area and 10 species with the minimum area (Table 2). Rattus rattus, as one of the top 100 most invasive alien species worldwide, had the maximum potential distribution area of 37.47 million $\mathrm{km}^{2}$, as expected. $R$. rattus originated in tropical Asia and spread through the Near East in Roman times before reaching Europe by the first century and spreading with European colonization across the world. As demonstrated in Table 2, the potential distribution area of all 10 species exceeds 28 million $\mathrm{km}^{2}$, and the average area is 31.49 million $\mathrm{km}^{2}$. Among the 10 species, $R$. rattus is the only animal species whereas the rest are plant species, thereby demonstrating the great invasive potential of plant alien species. Among the 10 species with the minimum potential distribution area, Dioscorea oppositifolia and Chenopodium hybridum are plant species, Carijoa riisei is a coral species, and the rest are animal species. The average potential distribution area of these 10 species is 0.30 million $\mathrm{km}^{2}$.

Given that invasive species management practices (including their use and eradication, etc.) are implemented and applied by different countries or regions, the invasive species "richness" corresponding to each country or administrative region is actually useful [39]. In the present study, we determined the potential richness and identified 10 countries or administrative regions with maximum invasive species richness (Table 3). As influenced by environmental conditions and human activities, the Reunion, New Caledonia, South Africa, the United Kingdom, the United States of America, Uruguay, Portugal, Argentina, Australia, and New Zealand could be invaded by at least 100 alien species. Comparatively, Svalbard,

Table 3. 10 countries or regions with maximum invasive species richness and 10 countries or regions with minimum richness.

\begin{tabular}{|c|c|c|c|}
\hline \multicolumn{2}{|c|}{$\begin{array}{c}10 \text { countries (or region) } \\
\text { with maximum invasive } \\
\text { species richness }\end{array}$} & \multicolumn{2}{|c|}{$\begin{array}{r}10 \text { countries (or region) } \\
\text { with minimum invasive } \\
\text { species richness }\end{array}$} \\
\hline $\begin{array}{c}\text { Countries } \\
\text { (or region) }\end{array}$ & Richness & $\begin{array}{c}\text { Countries } \\
\text { (or region) }\end{array}$ & Richness \\
\hline New Zealand & 141 & Svalbard & 0 \\
\hline Australia & 130 & Mongolia & 4 \\
\hline Argentina & 119 & Niger & 6 \\
\hline Portugal & 117 & $\begin{array}{c}\text { United Arab } \\
\text { Emirates }\end{array}$ & 6 \\
\hline Uruguay & 114 & Kuwait & 7 \\
\hline $\begin{array}{c}\text { United States } \\
\text { of America }\end{array}$ & 113 & Qatar & 8 \\
\hline $\begin{array}{c}\text { United } \\
\text { Kingdom }\end{array}$ & 112 & Gambia & 11 \\
\hline South Africa & 109 & $\begin{array}{c}\text { Western } \\
\text { Sahara }\end{array}$ & 13 \\
\hline $\begin{array}{c}\text { New } \\
\text { Caledonia }\end{array}$ & 107 & Chad & 14 \\
\hline $\begin{array}{c}\text { Reunion } \\
\text { Cape Verde }\end{array}$ & 17 \\
\hline 100 & Cape & 6 \\
\hline
\end{tabular}




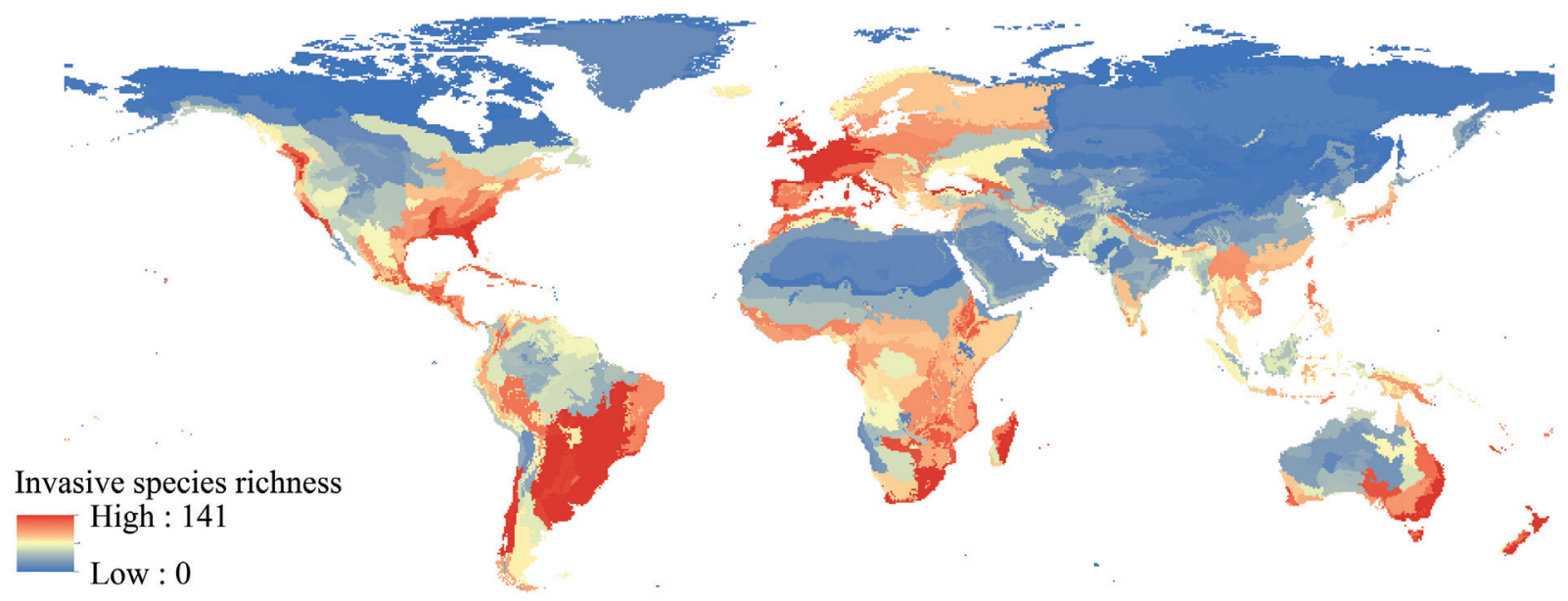

Fig. 3. Potential invasive species richness for different ecoregions.

Mongolia, Niger, the United Arab Emirates, Kuwait, Qatar, Gambia, Western Sahara, Chad, and Cape Verde are 10 countries or administrative regions with minimum invasive species richness (less than 20). The potential distribution was predicted based on presence samples, although the documented presence of samples per country is probably underestimated [40]. Thus, we speculated that the potential distribution is also underestimated, and the actual invasive species richness might be higher than the above-mentioned results.

Given that the exploration of species invasion in global ecoregions is important and urgently needed [41] (Thuiller 2005), we delineated the potential invasive species richness for different ecoregions worldwide (Fig. 3). Ecoregions at arid or cold regions (such as Alaska-Yukon Arctic) have relatively lower invasive species richness compared with the ecoregions with humid and warm climates (such as northern island temperate forests). The global spatial pattern of species richness in Fig. 3 agrees with previous works [1, 42, 43]. Based on this reliable prediction, we delineated 10 ecoregions with maximum invasive species richness. The 10 ecoregions include northern island temperate forests, east Australian temperate forests, humid pampas, Cantabrian mixed forests, southeast Australian temperate forests, Uruguayan savana, Atlantic mixed forests, Celtic broadleaf forests, Cantebury-Otago Tussock grasslands, and New Caledonia rainforests (Table 4). The average invasive species richness is 118. Among the 10 ecoregions with the maximum invasive species richness, seven are forest ecoregions, thereby confirming the previously reported high pressure of invasive species in global forest ecoregions [44]. By contrast, the Alaska-Yukon Arctic, Taiga Gordillera, southern Arctic, northern Arctic, western taiga shield, Arctic Cordillera, Yamal-Gydan Tundra, Taimyr-Central SiberianTundra, Novosibirsk islands Arctic desert, and the Daurian Forest Steppe are 10 ecoregions with minimum invasive species richness (richness equals 0 ), as shown in Table 4, thereby demonstrating the low invasion risk in these terrestrial ecoregions. However, marine ecoregions

Table 4. 10 ecoregions with maximum invasive species richness and 10 ecoregions with minimum richness.

\begin{tabular}{|c|c|c|c|}
\hline \multicolumn{2}{|c|}{10 ecoregions with maximum invasive species richness } & \multicolumn{2}{|c|}{10 ecoregions with minimum invasive species richness } \\
\hline Ecoregions & Richness & Richness \\
\hline North Island temperate forests & 141 & Taiga Cordillera & 0 \\
\hline East Australian temperate forests & 130 & Southern Arctic & 0 \\
\hline Humid Pampas & 119 & Northern Arctic & 0 \\
\hline Cantabrian mixed forests & 117 & Western Taiga Shield & 0 \\
\hline Southeast Australian temperate forests & 115 & Arctic Cordillera & 0 \\
\hline Uruguayan Savana & 114 & Yamal-Gydan Tundra & 0 \\
\hline Atlantic mixed forests & 113 & Taimyr-Central Siberian Tundra & 0 \\
\hline Celtic broadleaf forests & 112 & Novosibirsk Islands Arctic desert & 0 \\
\hline Cantebury-Otago Tussock grasslands & 110 & Daurian Forest Steppe & 0 \\
\hline New Caledonia rain forests & 107 & & 0 \\
\hline
\end{tabular}


at high latitudes have been invaded according to the corresponding research [45].

Selecting variables is a key issue in predicting the potential distribution of species (and/or alien species). In general, the selection of candidate variables significantly depends on data availability $[22,46]$. Bioclimatic variables (i.e., the Worldclim represents annual trends and the extremes of temperature and precipitation) were selected in the present study. However, the existing collinearity among these variables (which are actually interpolated based on DEM), including excessive bioclimatic variables, may result in overfitting (excessive restriction from bioclimatic variables, causing narrow geographic range) of the species distribution models. Thus, a suitable strategy (i.e., computing the correlation coefficient among variables and excluding these values with high correlations) is needed in the selection of candidate bioclimatic variables. The use of the selected bioclimatic variables is insufficient to delineate the external conditions of the species. Indirect variables (such as TWI and ASR) that are related to causal mechanisms behind species distribution are also important; the indirect variables may occasionally be even more important than bioclimatic variables, as shown in Table 1. The elucidation of causal mechanisms and the inclusion of indirect environmental variables are important to model the potential distribution of alien invasive species.

As demonstrated in Table 1, human activities have significantly affected the dispersion of alien plant species. Moreover, the relatively high geographic similarity between the spatial patterns of the human influence index and the species richness presented in Fig. 2 have confirmed this effect. The intended or unintended introduction of alien plant species to new areas primarily has resulted in the high correlation. Previous studies demonstrated that international trading, such as merchandise imports, is the most important explanatory variable that determines the richness of several invasive alien species [47, 48]. Therefore, we suggest that the different types of variables correlated with human activities should be included when modeling the potential distribution of alien plant species. This inclusion is important when predicting the distribution corresponding to current environmental conditions because the current spatial pattern of human activities can be obtained, as shown in this study.

The interactions between native and alien species and those among alien species, as well as other biotic factors, were not considered in the present study. The function of biotic interactions, such as predation and competition, should be elucidated when the actual distribution (realized niche) is modeled and mapped [49]. A possible comparative approach is the identification of biotic relationships and inclusion of biotic interactions to model species distribution [50]. Nonetheless, challenges are observed when establishing models of potential alien species distribution that originate from different regions with varied climates, particularly when the target species exhibits biotic interactions $[51,52]$.
After variable selection, a subsequent issue is the selection of species distribution models. In addition to the models used in the present study, candidate models also include the generalized additive model, boosted regression tree, genetic algorithm for rule-set prediction, and multivariate adaptive regression splines, among others. These models can be classified into two categories, namely the models based on presence-absence data (PA model) and the models with presence-only data (PO model). The basic criterion for selecting a candidate model is the collected data; the PO model can be used for prediction when presence data are collected, whereas the PA model is suitable when reliable absence data are also collected [53]. Acceptable results can be obtained from the prediction provided by one of these models, but a more confident potential distribution can only be predicted with the ensemble approach [54].

The adaptive evolution of a species is another source of uncertainty. Species distribution models assume that the relationship between species richness and environmental characteristics is stable within the timescale of the projection [48]. This assumption is challenging when we consider species that undergo microevolution (genetic variation) to adapt to climate change. The traits that determine the ecological niche of a species are universal between and within populations; thus, species can adapt to new climatic conditions [55-58]. However, macroevolutionary evidence shows rapid shifts in climatic niches [8]. Researchers have proposed that the influence of evolution on species distribution should be established because of its potential effect on the spatial distributions of species [55]. Species also exhibit dispersal ability that enables them to track proper environmental conditions and cope with various pressures, such as climate change, by migrating at a sufficient rate. Although climate change sufficiently presents a large spatial and/or long temporal scale pattern of species migration, the ability of a species to migrate rapidly across large distances is also possible [1]. Therefore, the correlated prediction under the existing climatic conditions is reasonable. Under this condition, the potential distribution is modeled with the present records (presence and absence), which are the real responses of a species to the climatic and other influencing variables. However, current records are useless when modeling future potential distributions because species rapidly respond to environmental changes. Consequently, modeling the potential distribution of a species under future climatic conditions may pose significant challenges when the geographic responses of species to changing climate conditions are not considered [6].

The potential distribution of alien species has been discussed in numerous studies. Some of these studies focused on the response of the geographic distribution of alien species to climate changes. We believe that the previous results are misleading because of the following reasons. First, the interactions among species are still not completely understood, and how these interactions will respond to climate change remains ambiguous. Second, 
scenarios that consider human activity are difficult to obtain. This study demonstrated that human activity may contribute to a higher extent than the bioclimatic and topographic layers.

\section{Acknowledgements}

This work was funded by the National Natural Science Foundation of China (Nos. 41361098 and 31500398). Special thanks to the two anonymous reviewers for their valuable comments.

\section{References}

1. BELLARD C., THUILLER W., Leroy B., et al. Will climate change promote future invasion? Global. Change. Biol., 19, 3740, 2013.

2. ZHU G., BU W., GAO Y. Potential geographic distribution of brown marmorated stink bug invasion (Halyomorpha halys). PLOS ONE, 7, e31246, 2012.

3. PRAKASH S., BALAMURUGAN J., KUMAR T.A. Invasion and richness of reef-inhabiting fishes in the Vellar estuary, southeast coast of India, especially the lionfish Pterois volitans Linnaeus. Curr. Sci., 103, 941, 2012.

4. MÜLLEROVÁ J., PERGL J., PYŠEK P. Remote sensing as a tool for monitoring plant invasions: Testing the effects of data resolution and image classification approach on the detection of a model plant species Heracleum mantegazzianum (giant hogweed). Int. J. Appl. Earth Observ. Geoinf., 25, 55, 2013.

5. FICETOLA G.F., THUILLER W., MIAUD C. Prediction and validation of the potential global distribution of a problematic alien invasive species - the American bullfrog. Divers. Distrib., 13, 476, 2007.

6. ELITH J., KEARNEY M., PHILLIPS S. The art of modelling range-shifting species. Methods. Ecol. Evol., 1, 330, 2010.

7. BERTELSMEIER C., GUÉNARD B., COURCHAMP F. Climate Change May Boost the Invasion of the Asian Needle Ant. PLOS ONE, 8, e75438, 2013.

8. MEDLEY K.A. Niche shifts during the global invasion of the Asian tiger mosquito, Aedes albopictus Skuse (Culicidae), revealed by reciprocal distribution models. Global. Ecol. Biogeogr., 19, 122, 2010.

9. GUO W.Y., LAMBERTINI C., LI X.Z. Invasion of Old World Phragmites australis in the New World: precipitation and temperature patterns combined with human influences redesign the invasive niche. Global Change Biol., 19, 3406, 2013.

10. BRADLEY B.A., OPPENHEIMER M., WILCOVE D.S. Climate change and plant invasions: restoration opportunities ahead? Global. Change Biol., 15, 1511, 2009.

11. GALLIEN L., DOUZET R., PRATTE S., et al. Invasive species distribution models - how violating the equilibrium assumption can create new insights. Global. Ecol. Biogeogr., 21, 1126, 2012.

12. MCCONNACHIE A.J., STRATHIE L.W., MERSIE W., et al. Current and potential geographical distribution of the invasive plant Parthenium hysterophorus (Asteraceae) in eastern and southern Africa. Weed. Res., 51, 71, 2011.

13. SEABLOOM E.W., WILLIAMS J.W., SLAYBACK D. Human impacts, plant invasion, and imperilled plant species in California. Ecol. Appl., 16, 1338, 2006.

14. PEJCHAR L., MOONEY H.A. Invasive species, ecosystem services and human well-being. Trends. Ecol. Evol., 24, 497,
2009.

15. PYŠEK P., JAROŠÍK V., HULME P.E., et al. Disentangling the role of environmental and human pressures on biological invasions across Europe. Proc. Natl. Acad. Sci. USA., 107, 12157, 2010.

16. WICHMANN M.C., ALEXANDER M.J., SOONS M.B. Human-mediated dispersal of seeds over long distances. Proc. R. Soc. B., 276, 523, 2009.

17. Global Biodiversity Information Facility (http://www.gbif. org/). Accessed 7 Nov 2012 to 12 Mar 2013.

18. Global Invasive Species Database (http://www.issg.org/ database). Accessed 7 Nov 2012 to 12 Oct 2013.

19. LOWE S., BROWNE M., BOUDJELAS S., et al. 100 of the World's Worst Invasive Alien Species A selection from the Global Invasive Species Database. The Invasive Species Specialist Group (ISSG) a specialist group of the Species Survival Commission (SSC) of the World Conservation Union (IUCN), Auckland, 2000.

20. HIJMANS R.J., CAMERON S.E., PARRA J.L., et al. Very high resolution interpolated climate surfaces for global land areas. I. J. Climatol., 25, 1965, 2005.

21. BEVEN K., KIRKBY M. A physically based, variable contributing area model of basin hydrology. Hydrol. Sci. J., 24, 43, 1979.

22. XU Z., FENG Z., YANG J., et al. Nowhere to Invade: Rumex crispus and Typha latifolia Projected to Disappear under Future Climate Scenarios. PLOS ONE 8, e70728, 2013.

23. GRABS T., SEIBERT J., BISHOP K., et al. Modeling spatial patterns of saturated areas: a comparison of the topographic wetness index and a dynamic distributed model. J. Hydrol., 373, 15, 2000.

24. PEI T., QIN CZ., ZHU A.X., et al. Mapping soil organic matter using the topographic wetness index: a comparative study based on different flow-direction algorithms and kriging methods. Ecol. Indic., 10, 610, 2010.

25. KUMAR L., SKIDMORE A.K., KNOWLES E. Modelling topographic variation in solar radiation in a GIS environment. Int. J. Geogr. Inf. Sci., 11, 475, 1997.

26. SANDERSON E.W., JAITEH M., LEVY M.A., et al. The Human Footprint and the Last of the Wild: The human footprint is a global map of human influence on the land surface, which suggests that human beings are stewards of nature, whether we like it or not. BioScience, 5, 891, 2002.

27. GUO Q., LIU Y. ModEco: an integrated software package for ecological niche modeling. Ecography, 33, 637, 2010.

28. BUSBY J.R. A biogeoclimatic analysis of nothofagus cunninghamii (hook.) oerst. In southeastern australia, Aust. J. Ecol., 11, 1, 1986.

29. CARPENTER G., GILLISON A.N., WINTER J. Domain - a flexible modeling procedure for mapping potential distributions of plants and animals. Biodivers. Conserv., 2, 667, 1993.

30. GUISAN A., EDWARDS T.C., HASTIE T. Generalized linear and generalized additive models in studies of species distributions: Setting the scene. Ecol. Model., 157, 89, 2002.

31. HASTIE T., TIBSHIRANI R., FRIEDMAN J. The elements of statistical learning: Data mining, inference and prediction. New York, Springer, 2001.

32. GUO Q., LIU Y. ModEco: an integrated software package for ecological niche modeling. Ecography, 33, 637, 2010.

33. GUO Q.H., KELLY M., GRAHAM C.H. Support vector machines for predicting distribution of sudden oak death in California. Ecol. Model., 182, 75, 2005.

34. DE'ATH G., FABRICIUS K. Classification and regression trees: A powerful yet simple technique for ecological data analysis. Ecology, 81, 3178, 2000. 
35. PAWLAK Z. Rough Sets: Theoretical Aspects of Reasoning About Data. Dordrecht, Kluwer Academic Publishing, 1991.

36. PHILLIPS S.J., ANDERSON R.P., SCHAPIRE R.E. MaxEnt entropy modeling of species geographic distribution. Ecol. Model., 190, 231, 2006.

37. LIU C., WHITE M., NEWELL G. Measuring and comparing the accuracy of species distribution models with presenceabsence data. Ecography, 34, 232, 2011.

38. ALLOUCHE O., TSOAR A., KADMON R. Assessing the accuracy of species distribution models: prevalence, kappa and the true skill statistic (TSS). J. Appl. Ecol., 43, 1223, 2006.

39. GENOVESI P. Eradications of invasive alien species in Europe: a review. Issues in Bioinvasion Science. Berlin, Springer Netherlands, 2005.

40. MCGEOCH M.A., BUTCHART S.H.M., SPEAR D., et al. Global indicators of biological invasion: species numbers, biodiversity impact and policy responses. Divers. Distrib., 16, 95, 2010.

41. THUILLER W., RICHARDSON D.M., PYŠEK P., et al. Niche-based modelling as a tool for predicting the risk of alien plant invasions at a global scale. Global. Change. Biol., 11, 2234, 2005.

42. BELLARD C., LECLERC C., LEROY B., et al. Vulnerability of biodiversity hotspots to global change. Global. Ecol. Biogeogr., 23, 1376, 2014.

43. TINGLEY R., VALLINOTO M., SEQUEIRA F., et al. Realized niche shift during a global biological invasion. P. Natl. Acad. Sci. USA., 111, 10233, 2014.

44. RICHARDSON D.M., REJMÁNEK M. Trees and shrubs as invasive alien species - a global review. Divers. Distrib., 17, 788, 2011.

45. MILLER A.W. Shipping and invasive species in the Arctic. In Marine invasive species in the Arctic (Eds, Fernandez L., Kaiser B., Vestergaard N.). Copenhagen, Norden, 2014.

46. DORMANN C.F. Promising the future? Global change projections of species distributions. Basic. Appl. Ecol., 8, 387, 2007.

47. WESTPHAL M.I., BROWNE M., MACKINNON K., et al. The link between international trade and the global distribution of invasive alien species. Biol.Invasions., 10, 391, 2008.
48. LENZEN M., MORAN D., KANEMOTO K., et al. International trade drives biodiversity threats in developing nations. Nature, 486, 109, 2012.

49. KEARNEY M., PORTER W. Mechanistic niche modelling: combining physiological and spatial data to predict species' ranges. Ecol. Lett., 12, 334, 2009.

50. PRESTON K.L., ROTENBERRY J.T., REDAK R.A., et al. Habitat shifts of endangered species under altered climate conditions: importance of biotic interactions. Global. Change. Biol., 14, 2501, 2008.

51. WILSON J.R., RICHARDSON D.M., ROUGET M., et al. Residence time and potential range: crucial considerations in modelling plant invasions. Divers. Distrib., 13, 11, 2007.

52. PRINGLE E.G., AKCAY E., RAAB T.K., et al. Water Stress Strengthens Mutualism Among Ants, Trees, and Scale Insects. PLOS Biol., 11, e1001705, 2013.

53. RAMASWAMI G., SUKUMAR R. Long-Term Environmental Correlates of Invasion by Lantana camara (Verbenaceae) in a Seasonally Dry Tropical Forest. PLOS ONE, 8, e 76995, 2013.

54. POTTIER J., DUBUIS A., PELLISSIER L., et al. The accuracy of plant assemblage prediction from species distribution models varies along environmental gradients. Global. Ecol. Biogeogr., 22, 52, 2013.

55. LAVERGNE S., MOUQUET N., THUILLER W., et al. Biodiversity and climate change: integrating evolutionary and ecological responses of species and communities. Ann. Rev. Ecol. Evol. Syst., 41, 321, 2010.

56. SAVOLAINEN O., PYHÄJÄRVI T., KNÜRR T. Gene flow and local adaptation in trees. Ann. Rev. Ecol. Evol. Syst., 38, 595, 2007.

57. SKELLY D.K., FREIDENBURG L.K. Evolutionary responses to climate change. eLS, 2010.

58. VISSER M.E. Keeping up with a warming world; assessing the rate of adaptation to climate change. Proc. R. Soc. B., 275, 649, 2008 